\title{
Warming temperatures and ectoparasitic sea lice impair internal organs in juvenile Atlantic salmon
}

\author{
Kate E. Medcalf ${ }^{1, *}$, Jeffrey A. Hutchings ${ }^{1,2,3}$, Mark D. Fast ${ }^{4}$, Anna Kuparinen ${ }^{5}$, \\ Sean C. Godwin ${ }^{1}$ \\ ${ }^{1}$ Department of Biology, Dalhousie University, Halifax, Nova Scotia B3H 4R2, Canada \\ ${ }^{2}$ Institute of Marine Research, Flødevigen Marine Research Station, 4817 His, Norway \\ ${ }^{3}$ Centre for Coastal Research, University of Agder, 4604 Kristiansand, Norway \\ ${ }^{4}$ Atlantic Veterinary College, University of Prince Edward Island, Charlottetown, Prince Edward Island C1A 4P3, Canada \\ ${ }^{5}$ Department of Biological and Environmental Sciences, University of Jyväskylä, 40014 Jyväskylä, Finland
}

\begin{abstract}
As a consequence of climate change and open net-pen salmon farming, wild Atlantic salmon Salmo salar are increasingly likely to encounter elevated temperatures and parasite abundances during their early marine migration. Such stressors can compromise fitness by diminishing liver energy stores and impairing cardiac muscle. To assess whether temperature and infestation by salmon lice Lepeophtheirus salmonis are important correlates of liver energy stores and cardiac muscle performance in juvenile salmon, we experimentally infested fish at 3 abundances of louse infestation (zero, low, and high) and 5 temperatures $\left(10,13,16,19\right.$, and $22^{\circ} \mathrm{C}$ ). At the end of the experiment (i.e. when sea lice reached adulthood), we calculated the percent dry weight of the liver (\%DWL; a proxy for liver energy stores) and cardiosomatic index (CSI; a proxy for cardiac muscle performance) of each fish and fitted 5 linear mixed-effects models to both of these responses. For both \%DWL and CSI, the best-supported model included additive fixed effects for both infestation level and temperature. Our top models predicted that, relative to zero infestation, high infestation reduces \%DWL by $5.7 \%$ (95\% CI: 5.3-6.2\%) and increases CSI by $15.9 \%$ $(14.4-18.0 \%)$, and low infestation reduces \%DWL by $2.6 \%(2.2-3.0 \%)$ and increases CSI by $7.8 \%$ $(6.7-10.0 \%)$. Our work suggests that stressors associated with ocean warming and coastal salmon aquaculture can compromise wild salmon fitness through the impairment of vital organs.
\end{abstract}

KEY WORDS: Climate change $\cdot$ Aquaculture $\cdot$ Salmon farms $\cdot$ Liver $\cdot$ Heart $\cdot$ Cardiosomatic index Lepeophtheirus salmonis $\cdot$ Hepatosomatic index

\section{INTRODUCTION}

The progression of climate change in the marine environment and the increasing global reliance on seafood-based protein necessitate assessment of their individual and combined implications for wild and farmed fish. Over the past 3 decades, the growing demand for seafood has resulted in a rapid global expansion of aquaculture operations (Thilsted et al. 2016), which have compensated for fisheries catches that plateaued in the late $20^{\text {th }}$ century (Pauly \& Zeller

\footnotetext{
*Corresponding author: kate.medcalf@dal.ca
}

2017). Of the numerous varieties of finfish aquaculture, marine net-pen salmon farming is by far the most profitable (FAO 2018). Consequently, salmon farming is now a major contributor to overall seafood production in coastal countries like Norway, the UK, Ireland, Chile, and Canada, with the sector's global production exceeding 2.4 million $\mathrm{t}$ and US $\$ 17.1$ billion annually (FAO 2020). Despite the recent growth and profitability of the salmon-aquaculture industry, concerns remain over its ecological consequences, as declines in wild Pacific (Oncorhynchus spp.) and

() The authors 2021. Open Access under Creative Commons by Attribution Licence. Use, distribution and reproduction are unrestricted. Authors and original publication must be credited. 
Atlantic salmon (Salmo salar) populations in several regions have been linked to genetic introgression and transmission of pathogens and parasites from farmed salmon (Ford \& Myers 2008, Karlsson et al. 2016, Vollset et al. 2016, Susdorf et al. 2018). Simultaneously, global sea surface temperatures (SSTs) have been increasing due to anthropogenic climate change, especially in the nearshore marine waters in which salmon-aquaculture facilities operate (Wong et al. 2014). Since there is no barrier between the internal net-pen environment and the surrounding coastal marine ecosystem, salmon-aquaculture operations stand to be affected by ocean warming.

The salmon louse Lepeophtheirus salmonis is a notorious parasite in the aquaculture industry due to its considerable economic and ecological effects. Estimates from Norwegian salmon farms suggest that these salmonid-specialist sea lice can cost the industry roughly $9 \%$ of revenues (Abolofia et al. 2017), which would correspond to billions of dollars in losses globally. Financial losses incurred by salmonaquaculture companies include not only the cost of anti-parasitic treatment but also the cost of reduced biomass, since sea-louse infestations influence growth and survival by compromising immune and osmoregulatory function (Pike \& Wadsworth 1999, Wagner et al. 2003, Finstad et al. 2010) and reducing food-conversion efficiency (Costello 2009a, Abolofia et al. 2017). While sea lice naturally occur on marine salmonids globally, they are especially prevalent in areas where salmon farms are present because farms act as sea-louse reservoirs that provide year-round infestation pressure to juvenile salmon that does not otherwise exist (Krkošek et al. 2007). The high densities of fish in salmon-aquaculture facilities provide ideal conditions for the proliferation of pathogens and parasites, and open net pens allow free transmission between wild and farmed populations (Krkošek et al. 2005, Costello 2009b). Due to the spatial overlap of aquaculture operations and salmon migration routes (Costello 2006, Krkošek 2017), louse transmission between sympatric farmed and wild salmon is inevitable (Marty et al. 2010, Peacock et al. 2013) and may negatively impact wild salmon populations (Connors et al. 2010, Krkošek et al. 2011, 2013, Vollset et al. 2016).

The compounding effects of climate change and coastal net-pen salmon farming may render sealouse infestation increasingly harmful to wild and farmed fish. Higher temperatures accelerate sealouse development (Johnson \& Albright 1991, Hamre et al. 2019); thus, louse outbreaks are anticipated to become more frequent and severe as louse genera- tion times shorten with climate warming (Bateman et al. 2016, Godwin et al. in press). Water temperature also regulates key physiological processes of salmonids, such as cardiorespiratory rate and metabolism (Jonsson \& Jonsson 2004), meaning that there are many potential pathways for interactions between sea-louse infestation and temperature. One such pathway is through the heart. Salmonid hearts perform less effectively at high temperature (e.g. dysrhythmia and reduced maximum stroke volume and cardiac output; Eliason et al. 2013), and louseinfested salmon have slower heart rates and critical swimming speeds than their non-infested counterparts (Wagner et al. 2003). Although direct and indirect effects of parasites on cardiac physiology and morphology have garnered recent interest (see review by Powell \& Yousaf 2017), nothing is known about such effects in the important social-ecological system of farmed and wild salmon. A second pathway through which the effects of sea-louse infestation and temperature may interact is depletions in energy reserves. Infestation by sea lice is likely to be energetically demanding for the host (Wagner et al. 2003, Wells et al. 2006). Elevated metabolic rates associated with higher temperatures can elicit rapid catabolism of energy reserves and induce greater nutritional requirements (Hevrøy et al. 2012), both of which can be reflected by the condition of the liver (Bruslé \& Anadon 1996). Considering that sea-louse infestation and temperature can have similar effects on the physiology of salmon, and that metabolic distress and nutrient deficiency are suspected to work in concert with other extrinsic stressors (e.g. pathogens) to cause mortality of apparently healthy farm fish (Dessen et al. 2020), rising sea temperatures may well interact with sea-louse infestation to exacerbate the physiological stress of infestation and further imperil salmon health.

While the effects of sea lice on host immune response and osmoregulatory function are generally well understood, comparatively few attempts have been made to discern how sea lice affect the internal organs of the host, and nothing is known about whether these potential effects are mediated by temperature. We performed a manipulative experiment to determine whether salmon-louse infestation affects the liver and heart - and, therefore, the energetic or physiological state - of juvenile Atlantic salmon, and whether water temperature interacts with infestation to exacerbate the effects of parasitism. To address these questions, we evaluated metrics of liver energy stores and cardiac muscle performance of the experimental fish, using the proxies of percent dry weight 
of the liver (\%DWL; Wuenschel et al. 2019) and cardiosomatic index (CSI; Frisk et al. 2020). We predicted that the effects of the parasites on their hosts would be accentuated at higher temperatures.

\section{MATERIALS AND METHODS}

To determine the effect of multiple stressors on energy stores and heart muscle performance in juvenile salmon, we analyzed the proportional size of the livers and hearts of Atlantic salmon post-smolts that had been experimentally infested with sea lice at 3 abundance levels (zero, low [mean $\pm \mathrm{SE}$ abundance $=$ $1.43 \pm 0.14$ lice fish $\left.^{-1}\right]$, and high $[6.76 \pm 0.41$ lice fish $^{-1}$ ]) in triplicate at 5 temperature treatments (10, $13,16,19$, and $22^{\circ} \mathrm{C}$ ).

\subsection{Experimental design}

We conducted our experiment at the Aquatron Research Facility of Dalhousie University in Halifax, Nova Scotia, Canada, as part of a larger study that used the same animals to investigate the temperature-dependent effects of sea lice on Atlantic salmon (Godwin et al. 2020). We held Saint John River strain Atlantic salmon post-smolts, sourced from Cape d'Or Aquaculture (Nova Scotia, Canada), in 8 recirculating seawater tanks (1750 l capacity, radius $=92 \mathrm{~cm}$, height of water line $=66 \mathrm{~cm}$ ) at $12^{\circ} \mathrm{C}$ for $12 \mathrm{~d}$. We anesthetized the fish in a $100 \mathrm{mg} \mathrm{l}^{-1}$ tricaine methanesulfonate (MS-222) seawater bath and inserted PIT tags $(7 \times 1.35 \mathrm{~mm}$; FDX-B Loligo Systems) into their abdominal cavities, following a standard protocol (Columbia Basin Fish and Wildlife Authority PIT Tag Steering Committee 1999). After a 10 d recovery period, we transferred the fish to a $300 \mathrm{l}$ tote (length $=97 \mathrm{~cm}$, width $=55 \mathrm{~cm}$, height $=58 \mathrm{~cm}$ ) in batches using a dip net. From the tote, we transferred each fish sequentially into $45 \times 70 \mathrm{l}$ flow-through experimental tanks (radius $=21 \mathrm{~cm}$, height of water line $=46 \mathrm{~cm}$ ) equipped with an adjustable air bubbler at the base of the standpipe and a weighted temperature logger $\left(\mathrm{HOBO}{ }^{\circledR}\right.$ Pendant ${ }^{\circledR}$ MX2201, Onset Computer) situated $5 \mathrm{~cm}$ below the surface. The water temperature in each tank was recorded every $3 \mathrm{~min}$ for the duration of the experiment. We administered feed ( $3 \mathrm{~mm}$ pellets; Nutra RC, Skretting) daily at $1 \%$ of the average body weight. We monitored mortalities, air input, and water inflow (mean $\pm \mathrm{SE}=1.40 \pm$ $0.14 \mathrm{l} \mathrm{min}^{-1}$ ) daily, measured dissolved oxygen saturation $(89.5 \pm 0.3 \%)$ every $1-2 \mathrm{~d}$, and checked $\mathrm{pH}$ (range: 7.2-7.7) and salinity (range: $28-32 \mathrm{ppt}$ ) intermittently. We calibrated the $\mathrm{pH}$ measurements to account for the effect of temperature and salinity.

We maintained the tanks at ambient seawater temperature (approximately $13^{\circ} \mathrm{C}$ ) for $25 \mathrm{~d}$ before adjusting the tank temperatures by a maximum of $1.5^{\circ} \mathrm{C} \mathrm{d}^{-1}$ to attain their randomly assigned temperatures $(10$, $13,16,19$, and $22^{\circ} \mathrm{C}$ ). We maintained these new temperatures for $10 \mathrm{~d}$. Due to delays in obtaining sea lice, we returned the tanks to ambient temperature to prevent differential size and condition from temperaturerelated growth prior to infestation. Once lice had been successfully hatched at the Huntsman Marine Science Centre (HMSC; St. Andrews, New Brunswick, Canada) $14 \mathrm{~d}$ later, we adjusted the tanks back to their assigned temperatures, again at a maximum of $1.5^{\circ} \mathrm{C}$ $\mathrm{d}^{-1}$. We permitted the fish to re-acclimate to the assigned temperatures for $10 \mathrm{~d}$ before anesthetizing them in a $100 \mathrm{mg} \mathrm{l}^{-1} \mathrm{MS}-222$ seawater bath to collect body weight and fork length measurements.

We infested the fish with sea lice $3 \mathrm{~d}$ after weighing them. The infective sea-louse copepodites (i.e. larvae) were cultured at HMSC from egg strings collected in August 2019 from sea-cage sites in the Bay of Fundy (New Brunswick, Canada). We introduced the copepodites to each tank according to our randomly assigned louse infestation treatments. Lowand high-infestation tanks received dilutions of a stock mixture with a known concentration of copepodites such that $150 \mathrm{ml}$ of liquid were added to each tank with a concentration of 0,15 , or 70 lice fish ${ }^{-1}$. The water inflow, which had been shut off prior to the addition of lice to facilitate louse settlement, was restored after $70 \mathrm{~min}$. Dissolved oxygen levels were unchanged during the $70 \mathrm{~min}$ infestation period, and temperatures shifted by a maximum of $1.5^{\circ} \mathrm{C}$. We infested the 45 experimental tanks in 3 stages separated by 20 min intervals, with each stage containing one of each possible unique temperature and infestation combination.

Less than $24 \mathrm{~h}$ following infestation, Hurricane Dorian swept through Halifax, Canada. The dramatic change in ambient seawater temperature in conjunction with equipment malfunction due to a power outage caused our lowest 3 temperatures $(10,13$, and $16^{\circ} \mathrm{C}$ ), which were maintained manually by technicians, to be warmer and more variable than planned for the first $10 \mathrm{~d}$ of the experiment (Fig. 1). The temperature groups remained distinct throughout this period, however, and the mean temperatures observed over the entire experiment $(10.50,13.63,16.25$, 19.03 , and $22.04^{\circ} \mathrm{C}$ ) remained within $0.63^{\circ} \mathrm{C}$ of the targeted temperatures $\left(10,13,16,19\right.$, and $\left.22^{\circ} \mathrm{C}\right)$. 


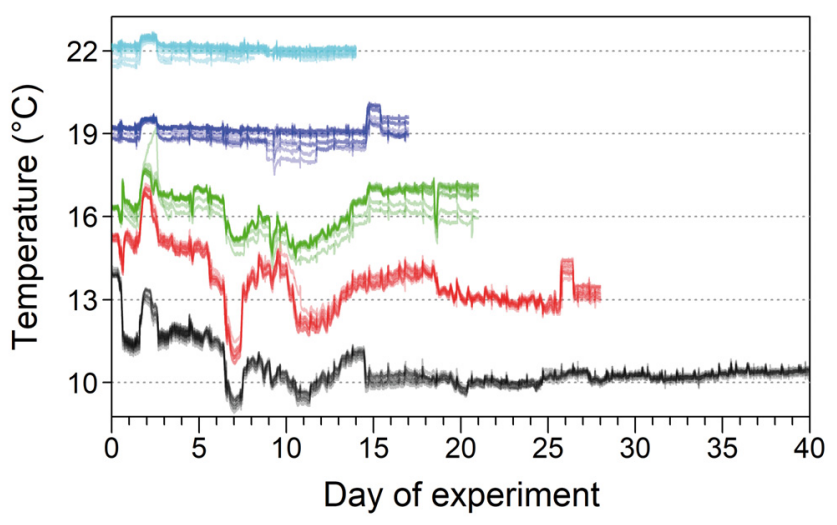

Fig. 1. Temperatures for experimental tanks from the time of infestation (Day 0) to the endpoint dissections. Each of the 45 tanks is represented by a semi-transparent line, and temperature groups $\left(10,13,16,19\right.$, and $\left.22^{\circ} \mathrm{C}\right)$ are identified by colors. The duration from infestation to endpoint dissections differed among temperature groups due to the temperaturedependent rate of sea-louse development. The first $10 \mathrm{~d}$ following infestation depict the impact of Hurricane Dorian on the variation in ambient water temperature. The 3 lowest temperature groups, which were adjusted manually rather than electronically, exhibited the greatest variability. Reproduced from the supplementary information of Godwin et al. (2020)

We euthanized approximately $40 \%$ of the fish in each tank once the lice had reached the pre-adult stage $(\mathrm{n}=286)$, then euthanized the remainder of the fish once the lice had reached the adult stage (i.e. 'endpoint dissections'; $\mathrm{n}=400$ ). The timing of these dissections varied with temperature group (e.g. $40 \mathrm{~d}$ for the $10^{\circ} \mathrm{C}$ group and $14 \mathrm{~d}$ for the $22^{\circ} \mathrm{C}$ group; see Table S1 in the Supplement at www.intres.com/articles/suppl/m660p161_supp.pdf) because sea lice develop faster at higher temperatures (Johnson \& Albright 1991). We used linear interpolation and extrapolation of the temperaturedependent development data presented by Hamre et al. (2019) to schedule sampling days for each of our temperature groups. To guarantee that all lice would have developed into adults by the endpoint dissection, we added an arbitrary $30 \%$ of the expected time to the predicted number of degreedays. On the prescribed sampling day, we euthanized the fish with a $250 \mathrm{mg} \mathrm{l}^{-1}$ overdose of MS222 and recorded their body weight and fork length. We systematically excised and weighed the heart and liver of each fish; for consistency across dissections, we removed auxiliary heart structures as described by Johansen et al. (2017) and retained only the ventricle and bulbus arteriosus. We stored the liver samples separately at $-20^{\circ} \mathrm{C}$ for subsequent processing.

\subsection{Organ analyses}

We used the livers and hearts from the endpoint dissections to calculate organosomatic indices for the 2 organs. Cardiosomatic index (CSI) and hepatosomatic index (HSI) are indicators of change in physiological and energy status (McPherson et al. 2011) frequently associated with stress response (Nilsson et al. 2018). In teleost fish, organosomatic liver indices positively correlate with liver energy density (Wuenschel et al. 2019), while CSI is a key indicator of cardiac muscle performance (Frisk et al. 2020, Waldrop et al. 2020). Since water can be incorporated into the liver in place of lipid, thereby confounding energy density estimation, we used percent dry weight of the liver (\%DWL) in place of HSI (Johnson et al. 2017). We dried the livers at $60^{\circ} \mathrm{C}$ to a constant weight, as described by Wuenschel et al. (2019), and allowed them to cool before weighing (Pacific Northwest Laboratories 1993). We determined the optimal time for ensuring 'constant weight' by comparing the weights of liver samples $(\mathrm{n}=20)$ dried for $16,24,40$, and $48 \mathrm{~h}$ at $60^{\circ} \mathrm{C}$ (Fig. S1); the percent change in mass from 24 to $48 \mathrm{~h}$ was negligible (mean $\pm \mathrm{SE}=-1.85 \pm 0.25 \%$ ), so we standardized sample drying time to $24 \mathrm{~h}$.

We calculated \%DWL in the same manner as Wuenschel et al. (2019):

$$
\% \mathrm{DWL}=100 \% \times\left(\frac{W_{\text {dry }}}{W_{\text {wet }}}\right)
$$

where $W_{\text {dry }}$ and $W_{\text {wet }}$ are liver dry and wet weight (g), respectively. We calculated CSI by modifying the ratio described by Johansen et al. (2017):

$$
\mathrm{CSI}=1000 \times\left(\frac{W_{\text {heart }}}{W_{\text {body }}}\right)
$$

where $W_{\text {heart }}$ is the wet weight (g) of the bulbus arteriosus and the ventricle, and $W_{\text {body }}$ is the intact body wet weight $(\mathrm{g})$. This ratio was multiplied by 1000 because the likelihood optimizer for mixed-effects modeling does not perform well with extremely small values. To prepare these data for model fitting, we identified and removed outlying observations indicative of data entry errors, using Tukey's fences and a conservative Tukey's constant of $k=4$ (Fig. S2), which resulted in the removal of 3 observations from the \%DWL data and 1 observation from the CSI data.

We fitted 5 linear mixed-effects models to the $\%$ DWL and CSI data. Normality and homoscedasticity of the residuals were confirmed visually using Q$\mathrm{Q}$ plots and plots of residuals against fitted values. The most complex model consisted of fixed effects for infestation level, temperature, and the multiplicative 
interaction between the 2 factors. The remaining models comprised the other 4 combinations of these parameters, including an intercept-only model. We used the mean temperature observed in each temperature group as a continuous variable in our analysis. To account for the clustering of variance within tanks, every model included a random effect on the intercept for tank (Tables S2 \& S3). We used Akaike's information criterion (AIC; Akaike 1974) to select the model which most appropriately described the $\%$ DWL and CSI data. We then determined the relative importance of each explanatory variable (RVI) by summing the weights of all models containing that variable. We conducted our analyses in $\mathrm{R}$ version 3.6.2 (R Core Team 2019), using the packages 'Ime4' (Bates et al. 2015) and 'MuMIn' (Bartón 2019).

\section{RESULTS}

Sea-louse infestation and temperature affected the liver and heart of juvenile Atlantic salmon. For both $\%$ DWL and CSI, the best-supported model included additive effects of temperature and infestation level but no interaction between them. The top \%DWL model was 3.40 AIC units lower than the secondranked model and accounted for $84 \%$ of overall model support (i.e. AIC weight; Table S2). \%DWL decreased with temperature and with increasing infestation level (Fig. 2). The model ranked second-best contained the additive and multiplicative effects of both temperature and infestation level and accounted for $15 \%$ of model support (Table S2). Infestation level

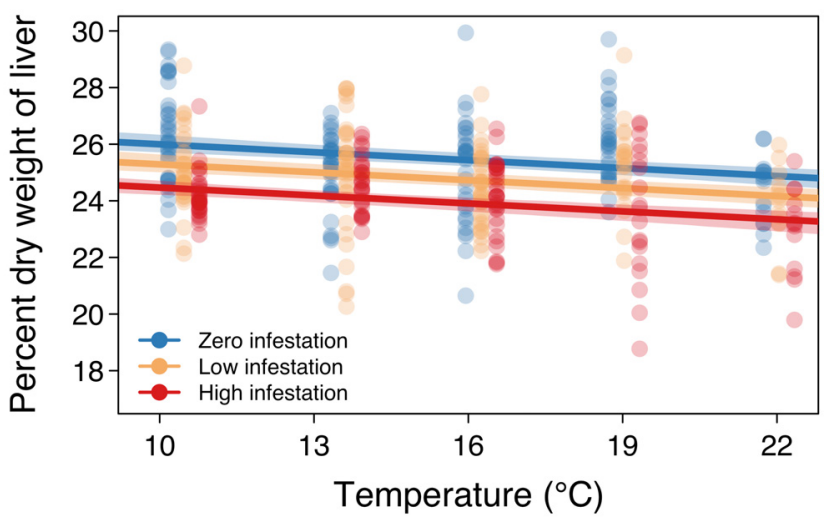

Fig. 2. Percent dry weight of the liver (\%DWL) in Atlantic salmon post-smolts at each temperature and sea-louse infestation level. Points represent observed \%DWL values (jittered by infestation level for visualization purposes), and the lines depict the mean predictions of the top \%DWL model (with bootstrapped $95 \% \mathrm{CI}$ ) for each of the 3 infestation levels had an RVI of 1.00, temperature had an RVI of 0.99, and their interaction had an RVI of 0.14 (Table S2). Our top model predicted that relative to zero infestation, high louse infestation reduced \%DWL by $5.7 \%$ (95\% CI: $5.3-6.2 \%)$ and low infestation reduced \%DWL by $2.6 \%(2.2-3.0 \%)$, on average (Table S3).

The top CSI model was 3.06 AIC units lower than the second most supported model and accounted for $82 \%$ of overall model support (Table S4). CSI increased with temperature and infestation level (Fig. 3). As for \%DWL, the model ranked second included the interaction between temperature and infestation level. Both of these correlates had an RVI of 1.00, and their interaction had an RVI of 0.17 (Table S4). Our top model predicted that high louse infestation increased CSI by $15.9 \%$ (95\% CI: $14.4-$ $18.0 \%$ ) and low infestation increased CSI by $7.8 \%$ $(6.7-10.0 \%)$, on average, relative to zero infestation (Table S5).

The louse abundances at the end of the experiment were 1.4 (95\% CI: 1.2-1.7) lice per fish for the lowinfestation treatment and $6.8(6.2-7.4)$ lice per fish for the high-infestation treatment (Table S6).

\section{DISCUSSION}

With increasing temperature and louse abundance, we observed a decrease in \%DWL and an increase in CSI. These findings suggest that liver energy stores and cardiac muscle performance are negatively impacted by elevated temperature and louse infestation. Contrary to our prediction and our

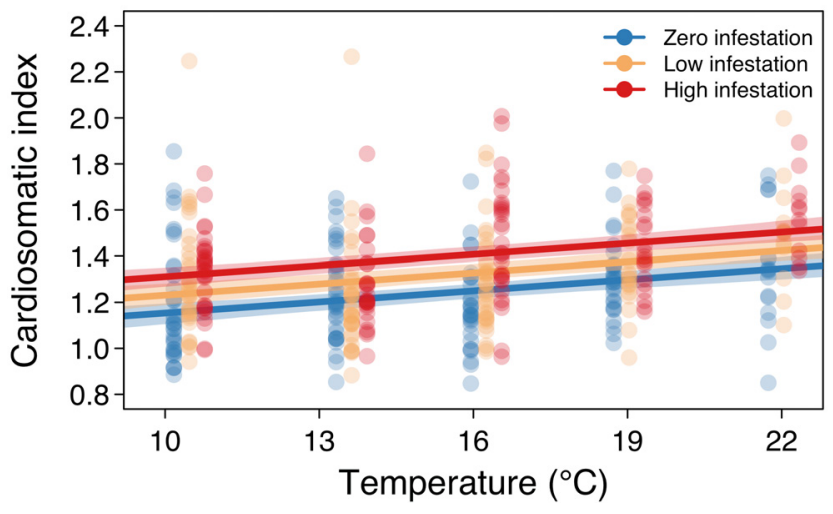

Fig. 3. Cardiosomatic index (CSI) of Atlantic salmon post-smolts at each temperature and sea-louse infestation level. Points represent observed CSI values (jittered by infestation level for visualization purposes), and the lines depict the mean predictions of the top CSI model (with bootstrapped $95 \% \mathrm{CI}$ ) for each of the 3 infestation levels 
recent work, which found that the effects of sea lice on salmon survival, growth, and body condition all worsened at higher temperatures (Godwin et al. 2020), the impacts of louse infestation on salmon livers and hearts were not exacerbated at higher temperatures. Our findings, contextualized as repercussions of the innate stress response, indicate that stressors associated with climate change and coastal salmon aquaculture may be detrimental to the fitness of farmed and wild Atlantic salmon.

Depletion of liver energy stores due to the effects of temperature and sea-louse infestation could have major implications for Atlantic salmon. Liver energy content and \%DWL exhibit a tight, positive correlation in teleost fish (Wuenschel et al. 2019), so the observed decreases in \%DWL indicate that liver energy stores would also likely be depleted in response to high temperatures and louse infestation. In carnivorous teleosts such as salmonids, liver energy stores predominantly comprise proteins and lipids (Hendry \& Beall 2004). Whereas protein content is governed by intrinsic factors, lipid levels are determined by both extrinsic and intrinsic factors (Shearer 1994), making these energy-dense and highly labile (McPherson et al. 2011) lipid stores vulnerable to depletion by pathogens and environment quality. Reproductive investment is believed to be contingent upon lipid-derived energy (Thorpe et al. 1998) and, in Atlantic salmon, low lipid stores are suggested to cause the postponement of maturation (Thorpe 2007). The quantity of stored energy has important consequences for the life history of salmon (Thorpe et al. 1998), which is punctuated by large energetic expenditures associated with migration and spawning, for which adequate energy reserves are crucial (Jonsson et al. 1991, Persson et al. 2018). The mechanism by which temperature and louse abundance may influence liver energy content may be through the effects of the stress hormone cortisol, which can cause macroscopic changes in salmonid liver tissue and depletions of energy stores (Harper \& Wolf 2009).

The fitness of Atlantic salmon could also be reduced by the impairment of cardiac muscle associated with temperature and parasite stress. Although heart growth is often adaptive in salmonids (e.g. for spawning and cold acclimatization), cortisol-induced heart growth is maladaptive because it is associated with reduced cardiac efficiency and swimming performance (Johansen et al. 2017). Since elevated blood cortisol concentration is one of the primary physiological responses of salmonids to high temperatures (Chadwick \& McCormick 2017, Madaro et al. 2018) and sea-louse infestation (Bowers et al. 2000, Tveiten et al. 2010), our findings suggest that juvenile Atlantic salmon experience maladaptive heart growth as a consequence of these 2 stressors. Fish in warmer conditions or that are infested by sea lice may therefore be at higher risk of mortality, as abnormal heart morphology decreases resilience to environmental or aquaculture-related stress (Poppe et al. 2003).

The temperatures and sea-louse infestation levels used in our experiment were good representations of predicted coastal ocean temperatures and the range of louse abundances observed on salmon farms. The experimental temperatures are similar to average summer near-surface temperatures in Atlantic Canada, which typically lie between 10 and $17^{\circ} \mathrm{C}$ but have been recorded to exceed $22^{\circ} \mathrm{C}$ (i.e. our highest experimental temperature) (Brewer-Dalton et al. 2015). Since average summer SSTs for coastal regions in eastern Canada are predicted to be approximately $4^{\circ} \mathrm{C}$ higher by mid-century than they were at the turn of the $21^{\text {st }}$ century (Greenan et al. 2018), the range of our experimental temperatures are relevant for future coastal marine conditions. The experimental infestation levels fall within - and, in fact, below the sea-louse abundances observed in Atlantic salmon farming operations in recent years (Atlantic Canada Fish Farmers Association 2020). Salmon farms in Atlantic Canada have much higher louse abundances than those in Pacific Canada or Europe, so we selected sea-louse infestation levels that are reflective of farm conditions in Atlantic Canada yet globally relevant. The paucity of publicly available data on louse abundances on wild juvenile Atlantic salmon prevents comparison between wild infestations and our experimental abundances.

Atlantic salmon aquaculture may benefit from a greater understanding of the effects of temperature and louse abundance on the condition of young fish. Our findings indicate that, as coastal temperatures inevitably increase, efforts to suppress louse outbreaks will be essential to minimize the effects of sea lice on farmed fish. These mitigation efforts may be even more crucial moving forward, given the capacity of temperature and louse effects to create a positive feedback mechanism that could exacerbate stress in salmonids. Thermal stress causes immune suppression in fish (Pickering \& Pottinger 1995), rendering them more vulnerable to parasitism (Bailey et al. 2017) and, potentially, increasing deleterious effects associated with higher parasite loads (Tørud \& Håstein 2008, Britton et al. 2011). Elevated temperatures also lead to higher rates of louse development and, therefore, accelerated louse generation time 
and population growth (Stien et al. 2005, Costello 2006, Groner et al. 2014). Indeed, at the highest temperature in our experiment $\left(22^{\circ} \mathrm{C}\right)$, salmonid hosts experience 2 generations of sea-louse infestation for every one generation at our lowest temperature $\left(10^{\circ} \mathrm{C}\right)$. It is also possible that the effects of the first louse generation may make hosts more vulnerable to the effects of subsequent generations. Our experiment isolated the effects of one louse generation, but there is ample opportunity for meaningful investigation into the relative impacts of lice integrated over multiple generations, either through a modeling or laboratory-based approach.

Recognizing how temperature and sea lice influence liver energy stores and heart muscle condition of juvenile Atlantic salmon could provide opportunities to enhance stewardship of wild populations. While the response of wild fish may differ from that of the fish in our experiment, which were sourced from a commercial hatchery, the effect of these stressors on the liver and heart was clear. Depleted liver energy stores or impaired heart muscle performance may be detrimental to the fitness of wild salmon whose life histories include massive migrations that demand substantial energy expenditure (Jonsson et al. 1991, Persson et al. 2018). Since smoltification depletes energy stores (Sheridan 1989), juvenile salmon undertaking a coastal migration from their natal freshwater systems to the open ocean (Thorstad et al. 2012) may be disproportionately impacted by stressors such as parasitism and temperature that further exhaust energy stores. Furthermore, juveniles with scarce energy reserves are less capable of surviving their migration and overwintering period (Finstad et al. 2004). Although energy may be re-allocated in a manner that enhances survival rather than growth or reproductive investment, such energetic trade-offs can alter life history traits (e.g. fecundity, size at maturity, age at maturity), and individual fitness may still decline (Roff 1992). Wild Atlantic salmon populations are in decline globally (Nehlsen et al. 1991, Chaput 2012), and sea-louse transmission from salmon farms may contribute to reductions in wild salmon recruitment (Connors et al. 2010, Krkošek et al. 2011, 2013, Vollset et al. 2016). From a conservation perspective, it is important to identify regions and populations at particular risk of the compounding effects of ocean warming and net-pen salmon aquaculture and consider whether current parasite management practices on farms are sufficient.

Both wild and farmed Atlantic salmon are increasingly exposed to stressors such as rising ocean temperatures and parasitism by sea lice. Our findings indicate that liver energy stores and heart muscle performance of juvenile Atlantic salmon are influenced by the additive effects of temperature and louse infestation, and thus indicate the need to consider how the consequences of sea-louse outbreaks may change as coastal oceans continue to warm. In an era where global food security is becoming increasingly reliant on aquaculture and the effects of climate change are manifesting at the ecosystem level, it is crucial to understand the potential ramifications of their combined impacts on key socialecological systems like farmed and wild salmon.

Acknowledgements. We thank J. Eddington, S. Fowler, L. Jarrett, and G. Tobin-Huxley at Dalhousie's Aquatron for facilitating this project in spite of delays and weatherrelated disruptions. We are grateful to S. Purcell and D. Michaud from the Atlantic Veterinary College for their expertise and resource sharing, to K. Gilmour for discussion, and to Huntsman Marine Science Centre for their involvement in procuring sea-louse copepodites, made possible by the Mitigating Impacts of Climate Change in Salmon Aquaculture (MICCSA) grant funded by the ACOA-AIF program. We acknowledge S. Barrett, S. Ferderber-Skripsky, G. Mullin, S. Williams, and many other volunteers for their invaluable assistance in fish husbandry and dissections. This research was funded by a Liber Ero Postdoctoral Fellowship (to S.C.G.), an Atlantic Salmon Conservation Foundation Research Grant (to S.C.G. and J.A.H.), 2 Natural Sciences and Engineering Research Council Discovery Grants (to J.A.H. [170146-2013] and A.K. [04249-2015]), the Academy of Finland (to A.K.), and the European Research Council (COMPLEX-FISH 770884 to A.K.). The present study reflects only the authors' views; the European Research Council is not responsible for any use that may be made of the information it contains. The use of animals for this research was in accordance with Dalhousie University Animal Ethics protocol 19-015.

\section{LITERATURE CITED}

Abolofia J, Asche F, Wilen JE (2017) The cost of lice: quantifying the impacts of parasitic sea lice on farmed salmon. Mar Resour Econ 32:329-349

Akaike H (1974) A new look at the statistical model identification. IEEE Trans Automat Contr 19:716-723

Atlantic Canada Fish Farmers Association (2020) 2019 New Brunswick annual sea lice management report. https:// static1.squarespace.com/static/56e827cb22482efe36420c65 /t/5e78da81abfcd65eb6925293/1584978564098/2019+Sea +Lice+Mgt+Report+Mar+13+2020.pdf

Bailey C, Segner H, Casanova-Nakayama A, Wahli T (2017) Who needs the hotspot? The effect of temperature on the fish host immune response to Tetracapsuloides bryosalmonae the causative agent of proliferative kidney disease. Fish Shellfish Immunol 63:424-437

* Bartón K (2019) MuMIn: multi-model inference, v. 1.43.1. https://CRAN.R-project.org/package=MuMIn

* Bateman AW, Peacock SJ, Connors B, Polk Z, Berg D, Krkošek M, Morton A (2016) Recent failure to control sea louse outbreaks on salmon in the Broughton Archi- 
pelago, British Columbia. Can J Fish Aquat Sci 73: 1164-1172

Bates D, Mächler M, Bolker B, Walker S (2015) Fitting linear mixed-effects models using lme4. J Stat Softw 67:1-48

Bowers JM, Mustafa A, Speare DJ, Conboy GA, Brimacombe M, Sims DE, Burka JF (2000) The physiological response of Atlantic salmon, Salmo salar L., to a single experimental challenge with sea lice, Lepeophtheirus salmonis. J Fish Dis 23:165-172

Brewer-Dalton K, Page FH, Chandler P, Ratsimandresy A (2015) Oceanographic conditions of salmon farming areas with attention to those factors that may influence the biology and ecology of sea lice, Lepeophtheirus salmonis and Caligus spp., and their control. DFO Can Sci Advis Sec Res Doc 2014/048. http://publications.gc.ca/ collections/collection_2015/mpo-dfo/Fs70-5-2014-048eng.pdf

Britton JR, Pegg J, Williams CF (2011) Pathological and ecological host consequences of infection by an introduced fish parasite. PLOS ONE 6:e26365

Bruslé J, Anadon GG (1996) The structure and function of fish liver. In: Munshi JSD, Dutta HM (eds) Fish morphology: horizon of new research. AA Balkema, Brookfield, VT, p 77-93

Chadwick JG, McCormick SD (2017) Upper thermal limits of growth in brook trout and their relationship to stress physiology. J Exp Biol 220:3976-3987

Chaput G (2012) Overview of the status of Atlantic salmon (Salmo salar) in the North Atlantic and trends in marine mortality. ICES J Mar Sci 69:1538-1548

Columbia Basin Fish and Wildlife Authority PIT Tag Steering Committee (1999) PIT tag marking procedures manual. Columbia Basin Fish and Wildlife Authority, Portland, OR

Connors BM, Krkošek M, Ford J, Dill LM (2010) Coho salmon productivity in relation to salmon lice from infected prey and salmon farms: salmon populations and parasites from aquaculture. J Appl Ecol 47:1372-1377

Costello MJ (2006) Ecology of sea lice parasitic on farmed and wild fish. Trends Parasitol 22:475-483

* Costello MJ (2009a) The global economic cost of sea lice to the salmonid farming industry. J Fish Dis 32:115-118

Costello MJ (2009b) How sea lice from salmon farms may cause wild salmonid declines in Europe and North America and be a threat to fishes elsewhere. Proc R Soc B 276: 3385-3394

* Dessen JE, Østbye TK, Ruyter B, Bou M, Thomassen MS, Rørvik KA (2020) Sudden increased mortality in large seemingly healthy farmed Atlantic salmon (Salmo salar L.) was associated with environmental and dietary changes. J Appl Aquacult, doi.org/10.1080/10454438. 2020.1726237

* Eliason EJ, Clark TD, Hinch SG, Farrell AP (2013) Cardiorespiratory collapse at high temperature in swimming adult sockeye salmon. Conserv Physiol 1:cot008

FAO (Food and Agriculture Organization of the United Nations) (2018) The state of world fisheries and aquaculture. FAO, Rome

FAO (2020) Global aquaculture production statistics, 1950-2018. Fisheries and Aquaculture Information and Statistics Branch. FAO, Rome

Finstad AG, Ugedal O, Forseth T, Næsje TF (2004) Energyrelated juvenile winter mortality in a northern population of Atlantic salmon (Salmo salar). Can J Fish Aquat Sci 61:2358-2368
Finstad B, Bjørn PA, Todd CD, Whoriskey F, Gargan PG, Forde G, Revie CW (2010) The effect of sea lice on Atlantic salmon and other salmonid species. In: Aas $\varnothing$, Einum S, Klemetsen A, Skurdal J (eds) Atlantic salmon ecology. Wiley-Blackwell, Oxford, p 253-276

Ford JS, Myers RA (2008) A global assessment of salmon aquaculture impacts on wild salmonids. PLOS Biol 6:e33

Frisk M, Høyland M, Zhang L, Vindas MA, Øverli Ø, Johansen IB (2020) Intensive smolt production is associated with deviating cardiac morphology in Atlantic salmon (Salmo salar L.). Aquaculture 529:735615

* Godwin SC, Fast MD, Kuparinen A, Medcalf KE, Hutchings JA (2020) Increasing temperatures accentuate negative fitness consequences of a marine parasite. Sci Rep 10:18467

*Godwin SC, Krkosek M, Reynolds JD, Bateman AW (in press) Sea-louse abundance on salmon farms in relation to parasite-control policy and climate change. ICES J Mar Sci fsaa173

Greenan BJW, James TS, Loder JW, Pepin P and others (2018) Changes in oceans surrounding Canada, Chapter 7. In: Bush E, Lemmen DS (eds) Canada's changing climate report. Government of Canada, Ottawa, p 343-423

* Groner ML, Gettinby G, Stormoen M, Revie CW, Cox R (2014) Modelling the impact of temperature-induced life history plasticity and mate limitation on the epidemic potential of a marine ectoparasite. PLOS ONE 9:e88465

*Hamre LA, Bui S, Oppedal F, Skern-Mauritzen R, Dalvin S (2019) Development of the salmon louse Lepeophtheirus salmonis parasitic stages in temperatures ranging from 3 to $24^{\circ} \mathrm{C}$. Aquacult Environ Interact 11:429-443

*Harper C, Wolf JC (2009) Morphologic effects of the stress response in fish. ILAR J 50:387-396

* Hendry AP, Beall E (2004) Energy use in spawning Atlantic salmon. Ecol Freshw Fish 13:185-196

*Hevrøy EM, Waagbø R, Torstensen BE, Takle $\mathrm{H}$ and others (2012) Ghrelin is involved in voluntary anorexia in Atlantic salmon raised at elevated sea temperatures. Gen Comp Endocrinol 175:118-134

Johansen IB, Sandblom E, Skov PV, Gräns A and others (2017) Bigger is not better: cortisol-induced cardiac growth and dysfunction in salmonids. J Exp Biol 220:2545-2553

Johnson BM, Pate WM, Hansen AG (2017) Energy density and dry matter content in fish: new observations and an evaluation of some empirical models. Trans Am Fish Soc 146:1262-1278

* Johnson SC, Albright LJ (1991) Development, growth, and survival of Lepeophtheirus salmonis (Copepoda: Caligidae) under laboratory conditions. J Mar Biol Assoc UK 71:425-436

Konsson B, Jonsson N (2004) Factors affecting marine production of Atlantic salmon (Salmo salar). Can J Fish Aquat Sci 61:2369-2383

Jonsson N, Jonsson B, Hansen LP (1991) Energetic cost of spawning in male and female Atlantic salmon (Salmo salar L.). J Fish Biol 39:739-744

Karlsson S, Diserud OH, Fiske P, Hindar K (2016) Widespread genetic introgression of escaped farmed Atlantic salmon in wild salmon populations. ICES J Mar Sci 73: 2488-2498

* Krkošek M (2017) Population biology of infectious diseases shared by wild and farmed fish. Can J Fish Aquat Sci 74: 620-628

Krkošek M, Lewis MA, Volpe JP (2005) Transmission dynamics of parasitic sea lice from farm to wild salmon. Proc R Soc B 272:689-696 
Krkošek M, Gottesfeld A, Proctor B, Rolston D, Carr-Harris C, Lewis MA (2007) Effects of host migration, diversity and aquaculture on sea lice threats to Pacific salmon populations. Proc R Soc B 274:3141-3149

Krkošek M, Connors BM, Morton A, Lewis MA, Dill LM, Hilborn R (2011) Effects of parasites from salmon farms on productivity of wild salmon. Proc Natl Acad Sci USA 108:14700-14704

Krkošek M, Revie CW, Gargan PG, Skilbrei OT, Finstad B, Todd CD (2013) Impact of parasites on salmon recruitment in the Northeast Atlantic Ocean. Proc R Soc B 280: 20122359

Madaro A, Folkedal O, Maiolo S, Alvanopoulou M, Olsen RE (2018) Effects of acclimation temperature on cortisol and oxygen consumption in Atlantic salmon (Salmo salar) post-smolt exposed to acute stress. Aquaculture 497:331-335

Marty GD, Saksida SM, Quinn TJ (2010) Relationship of farm salmon, sea lice, and wild salmon populations. Proc Natl Acad Sci USA 107:22599-22604

*McPherson LR, Slotte A, Kvamme C, Meier S, Marshall CT (2011) Inconsistencies in measurement of fish condition: a comparison of four indices of fat reserves for Atlantic herring (Clupea harengus). ICES J Mar Sci 68:52-60

Nehlsen W, Williams JE, Lichatowich JA (1991) Pacific salmon at the crossroads: stocks at risk from California, Oregon, Idaho, and Washington. Fisheries 16:4-21

Nilsson J, Stien LH, Iversen MH, Kristiansen TS and others (2018) Part A. Knowledge and theoretical background. In: Noble C, Gismervik K, Iversen MH, Kolarevic J, Nilsson J, Stien LH, Turnbull JF (eds) Welfare indicators for farmed Atlantic salmon: tools for assessing fish welfare. Nofima, Tromsø, p 10-145

Pacific Northwest Laboratories (1993) Analytical Chemistry Laboratory (ACL) procedure compendium. Vol 2, Sample preparation methods. Pacific Northwest Laboratories, Richland, WA

Pauly D, Zeller D (2017) Comments on FAOs state of world fisheries and aquaculture (SOFIA 2016). Mar Policy 77 : 176-181

* Peacock SJ, Krkošek M, Proboszcz S, Orr C, Lewis MA (2013) Cessation of a salmon decline with control of parasites. Ecol Appl 23:606-620

Persson L, Leonardsson K, Alanärä A (2018) Manipulation of the energetic state of Atlantic salmon Salmo salar juveniles and the effect on migration speed. J Fish Biol 92:961-978

Pickering AD, Pottinger TG (1995) Biochemical effects of stress. In: Hochachka PW, Mommsen TP (eds) Biochemistry and molecular biology of fishes, Vol 5. Elsevier, Amsterdam, p 349-379

Pike AW, Wadsworth SL (1999) Sealice on salmonids: their biology and control. Adv Parasitol 44:233-337

* Poppe TT, Johansen R, Gunnes G, Tørud B (2003) Heart morphology in wild and farmed Atlantic salmon Salmo salar and rainbow trout Oncorhynchus mykiss. Dis Aquat Org 57:103-108

Powell MD, Yousaf MN (2017) Cardiovascular effects of disease: parasites and pathogens. Fish Physiol 36:435-470

R Core Team (2019) R: a language and environment for statistical computing. R Foundation for Statistical Computing, Vienna

Roff DA (1992) The evolution of life histories: theory and analysis. Chapman \& Hall, New York, NY

Shearer KD (1994) Factors affecting the proximate composi- tion of cultured fishes with emphasis on salmonids. Aquaculture 119:63-88

* Sheridan MA (1989) Alterations in lipid metabolism accompanying smoltification and seawater adaptation of salmonid fish. Aquaculture 82:191-203

Stien A, Bjørn PA, Heuch PA, Elston DA (2005) Population dynamics of salmon lice Lepeophtheirus salmonis on Atlantic salmon and sea trout. Mar Ecol Prog Ser 290: 263-275

Susdorf R, Salama NKG, Lusseau D (2018) Influence of body condition on the population dynamics of Atlantic salmon with consideration of the potential impact of sea lice. J Fish Dis 41:941-951

* Thilsted SH, Thorne-Lyman A, Webb P, Bogard JR, Subasinghe R, Phillips MJ, Allison EH (2016) Sustaining healthy diets: the role of capture fisheries and aquaculture for improving nutrition in the post-2015 era. Food Policy 61:126-131

Thorpe JE (2007) Maturation responses of salmonids to changing developmental opportunities. Mar Ecol Prog Ser 335:285-288

* Thorpe JE, Mangel M, Metcalfe NB, Huntingford FA (1998) Modelling the proximate basis of salmonid life-history variation, with application to Atlantic salmon, Salmo salar L. Evol Ecol 12:581-599

* Thorstad EB, Whoriskey F, Uglem I, Moore A, Rikardsen AH, Finstad B (2012) A critical life stage of the Atlantic salmon Salmo salar: behaviour and survival during the smolt and initial post-smolt migration. J Fish Biol 81:500-542

* Tørud B, Håstein T (2008) Skin lesions in fish: causes and solutions. Acta Vet Scand 50:S7

* Tveiten H, Bjørn PA, Johnsen HK, Finstad B, McKinley RS (2010) Effects of the sea louse Lepeophtheirus salmonis on temporal changes in cortisol, sex steroids, growth and reproductive investment in Arctic charr Salvelinus alpinus. J Fish Biol 76:2318-2341

* Vollset KW, Krontveit RI, Jansen PA, Finstad B and others (2016) Impacts of parasites on marine survival of Atlantic salmon: a meta-analysis. Fish Fish 17:714-730

* Wagner GN, McKinley RS, Bjorn PA, Finstad B (2003) Physiological impact of sea lice on swimming performance of Atlantic salmon. J Fish Biol 62:1000-1009

Waldrop T, Summerfelt S, Mazik P, Kenney PB, Good C (2020) The effects of swimming exercise and dissolved oxygen on growth performance, fin condition and survival of rainbow trout Oncorhynchus mykiss. Aquacult Res 51:2582-2589

*Wells A, Grierson CE, MacKenzie M, Russon IJ and others (2006) Physiological effects of simultaneous, abrupt seawater entry and sea lice (Lepeophtheirus salmonis) infestation of wild, sea-run brown trout (Salmo trutta) smolts. Can J Fish Aquat Sci 63:2809-2821

Wong PP, Losada IJ, Gattuso J, Hinkel J and others (2014) Coastal systems and low-lying areas. In: Field CB, Barros VR, Dokken DJ, Mach KJ and others (eds) Climate change 2014: impacts, adaptation, and vulnerability. Part A: Global and sectoral change aspects. Contribution of Working Group II to the Fifth Assessment Report of the Intergovernmental Panel on Climate Change. Cambridge University Press, Cambridge, p 361-409

*Wuenschel M, McElroy W, Oliveira K, McBride R (2019) Measuring fish condition: an evaluation of new and old metrics for three species with contrasting life histories. Can J Fish Aquat Sci 76:886-903

Submitted: July 6, 2020

Accepted: December 7, 2020

Proofs received from author(s): February 2, 2021
Editorial responsibility: Alistai
Hobart, Tasmania, Australia

Reviewed by: A. Teffer, M. J. Costello 